\title{
Reformulating the Notion of Intercultural Communication Style within a Rhetorical Frame
}

- Santosh Khadka

It is customary to think that every culture around the world has its own distinct communication style or pattern. People, for instance, talk of Chinese, Japanese, Nepalese or American communication style indicating that there exists a generalizable pattern of communication within each of these cultures or countries. A lot of research works in the field of intercultural communication uphold this and similar ideas about intercultural communication style. But my study complicates such notion and contends that both cultural and intercultural communication styles are rhetorical choices of the interactants therefore dynamic and/or non-generalizable in terms of some pre-existing assumptions about cultural or intercultural communication styles.

Communication style, as Dean Barnlund describes, includes "topics people prefer to discuss, their favorite forms of interaction-ritual, repartee, argument, and self-disclosureand the depth of involvement they demand, as well as the channel people rely upon" (as cited in Sheila Ramsey, 1998, p. 114). If we were to go with Darlund's formulation, then communication style encapsulates almost everything that communication is all about from topics to forms to media of communication. His notion of communication style also resonates with the views of many intercultural communication scholars, who believe that communication styles across cultures differ considerably in terms of topics, forms as well as the channels of interactions. While underscoring the differences in intercultural communication styles, they, however, stereotype the cultural communication styles by describing them in terms of some finite and fixed set of characteristics, which, I contend, is a grossly mistaken move these scholars unwittingly make.

One such instance can be located in Sheila Ramsey's (1998) article "Interactions between North Americans and Japanese: 
Considerations of Communication Style" where she compares cross-cultural communication styles of North Americans and Japanese individuals along three variables: (1) Orientation to interaction, (2) code preference, and (3) interaction format, and presents the variation across them as follows:

$\begin{array}{lll} & \text { North Americans } & \text { Japanese } \\ \text { 1. Orientation to Interaction } & \text { Locus of Self: Individualistic } & \text { Interpersonal } \\ & \text { View of Reality: Objective } & \text { Subjective } \\ \text { 2. Code Preference } & \text { Verbal (and nonverbal) } & \text { Nonverbal (and verbal) } \\ \text { 3. Interaction Format } & \text { Persuasive } & \text { Harmonizing } \\ & \text { Quantitative } & \text { Holistic } \\ & \text { Pragmatic } & \text { Process-Oriented }\end{array}$

As is evident from the chart above, Ramsey puts North Americans and Japanese individuals in opposite ends of the spectrum, which in itself is problematic in many ways. A question as simple as 'Does every North American individual tend to be persuasive in his/her interaction?' complicates Ramsey's categorizations. Obviously, not every North American is or can be persuasive neither is or can every Japanese be harmonizing in his/her interaction. Therefore, the evident problem in this study is the gross generalization of the communication style of a large section of people based on a limited set of data.

Some studies like that of Theodore A Avtgis, and Andrew S. Rancer's (2002) essay "Aggressive Communication Across Cultures: A Comparison of Aggressive Communication among United States, New Zealand, and Australia" have looked at the intercultural communication styles little more critically, but still not adequately. Avtgis and Rancer's study finds that in terms of aggressive communication, American students are more argumentative/aggressive than both Japanese and Korean 
students while Finish and Norwegian students are even more aggressive than American students. This finding is significant as it complicates the general intercultural notion that all lowcontext cultures like American, Finish and Norwegian display similar aggressive/argumentative behaviors. The study also discovers that students from New Zealand, a collectivist culture, are more argumentative than students from America, an individualist culture. This finding in particular complicates another intercultural notion that interactants from collective cultures tend to be indirect, and therefore less argumentative or aggressive. Though the findings of this study are striking, the problem with the research is still glaring. The researchers have treated whole nations as homogenous cultures and inductively inferred conclusions for the whole nations based on observations or interviews of/with few participants from each nation. These researchers have repeated the same set of errors in another study on non-verbal communication style too. In "Comparing Touch Apprehension and Affective Orientation between Asian-American and European-American Siblings," they examine and compare the touch apprehension and affective orientation of Asian-American and European-American siblings. They specifically look at the effect of culture on the display of emotion and touch behaviors in sibling relationships. Declaring differences in touch apprehension as the function of culture, they report some interesting findings such as that males are more touch avoidant than females; Japanese and Koreans are more touch avoidant than Americans; same sex people are more touch avoidant than opposite sex people and that culture and gender influence predisposition towards touch apprehension. Similarly, the study finds that Japanese Americans are more touch apprehensive than Americans or European Americans and that Asian cultures are low contact cultures compared to European cultures. Once again, like the studies discussed, the generalization here is massive. It could be the issue of sample size and related research methodology. The questions worth considering in that connection are: What sample size is adequate to draw conclusion about any culture or a community? Is it at all possible to make inferences about a 
large population from a small sample? What role does selfreflexivity play in reducing the methodological error? I think, these studies should have explicitly stated their limitations and qualified their findings to indicate partial validity. Without any qualification, sample-based conclusions are prone to irrelevance and partial representation. Even fully founded conclusions about cultures and individuals can turn invalid over time because both individuals and cultural practices evolve and change. Therefore, the findings of most of the studies about the intercultural communication styles seem to be problematic.

There is no dearth of such studies, however. Ellen Feghali's (1997) "Arab Cultural Communication Patterns" is another addition to such a corpus. She makes similar generalizing move while noting that an Arab values collectivism, hospitality, honor and hierarchical relations and their communicative style is characterized by repetition (p. 358), indirectness or high context, elaborateness, and affectiveness which stands in sharp contrast to American communication style guided by individualism, egalitarian social relations, and direct and objective approach. With regards to elaborateness, she says, "Where an American can adequately express an idea in 10 words, the Arabic speaker will typically use 100 words" (p. 359). I am surprised by the degree of assertiveness of this statement. I don't think anyone would totally agree with her assertion. Not every American or Arabic speaker operates exactly that way.

Bo Feng \& Brant R Burleson (2006) in "Exploring the Support Seeking Process across Cultures: Toward an Integrated Analysis of Similarities and Differences" continue this trend of generalization, but also complicate many assumptions underlying intercultural communication and intercultural communication styles. In connection with the cross-cultural support seeking styles, the authors note:

how people experience and express emotion, cope with upset, and seek support may vary in noticeable ways across cultures. Some of these variations may be largely matters of style (e.g., 
different ways of seeking support may be equally effective in different cultures), but others may have important functional consequences (e.g., some ways of seeking support may be more effective than others across cultures). (p. 244)

They report that people's value orientations and communication styles have an impact on "whether people seek support, how frequently they seek it, the type of support they seek, from whom they seek support, and the strategies used to seek it" (p. 246). Their study particularly looks at four critical aspects of support seeking: (a) the likelihood of seeking support (b) the types of support sought (c) the agents from whom support is sought (d) the strategies used when seeking support, and then report some interesting findings. Their study also challenges many pre-existing assumptions about cultural worldviews and values from around the world. As opposed to the general belief that members in collectivist cultures get spontaneous support from their networks than those in individualist cultures, the study finds the case to be otherwise because of the fact that the members in collectivist cultures value group harmony over everything else, and therefore don't actively seek support. The case is so precisely because with priority on group harmony, members of collectivist cultures are taught to tolerate suffering and sacrifice for the group welfare whereas members in individual cultures do not hold such values therefore actively seek support from potential helpers. Another similar finding is that Asians are more likely to opt for social withdrawal in times of stress or depression as opposed to members from Western individualist cultures, who are more likely to actively seek support in those situations. Social withdrawal is a coping strategy for Asians.

These insights apart, the study, however, brings out familiar results like the ones quoted here:

$[C]$ ollectivists are more likely to rely on high context communication than are individualists (Gudykunst, Matsumoto et al., 1996). This suggests collectivists are more likely than individualists to rely on the context to convey their need for 
support, as well as on covert support seeking strategies (e.g., undirected complaints about a problematic situation, hints, indirect expressions of distress such as sighing). In contrast, members of individualist cultures are typically socialized to be open in the expression of their thoughts, wants, and feelings as ways of both enhancing interpersonal understanding and maintaining personal psychological health (Markus \& Kitayama, 1994). Moreover, members of individualist cultures are more likely to engage in low-context communication (Gudykunst, Matsumoto et al., 1996); this means they are more likely than collectivists to rely on overt, direct support-seeking strategies (e.g., explicit statements of need, direct requests for assistance, overt nonverbal displays of distress such as crying). (p. 257-258)

This should have been the anticipated result of the study because it is widely held notion that high-context collective cultures use indirect strategies of verbal and non-verbal communication in contrast to low-context individual cultures, which tend to use direct strategies of communication. One striking finding of this study that has also become the point of departure for my essay, however, is the claim of the authors that all the cultural patterns and styles of support seeking as discussed above are undercut by an apparent "transcultural gender patterns in the likelihood of support seeking. In both collectivist and individualist cultures, women are more likely than men to seek support from others" (p. 253). This assertion also contradicts with the findings of a lot of other intercultural studies. Similarly, this prompts us to look for some transcultural style of communication. What could such a style be? What would it look like? I believe communication style as rhetorical move/choice even in intercultural context should be a step toward formulating a transcultural style of communication.

Theorization of intercultural communication style as rhetorical move is already long overdue because many of the existing assumptions about intercultural communication, and intercultural communication style have already been problematized. Suraj Kapoor, Catherine Konsky, and Janet Blue's (1997) “American and Indian Students' Preference for 
Horizontal and Vertical Individualism-Collectivism," is one such instance, which challenges deeply held binaries in intercultural communication like individual and collective, high-context and low-context, arguing that increasing global and intercultural flow of information and ideas are changing such continuums. For instance, mass communication, especially the TV programs being broadcast from individualist countries like the United States are shaping and reinforcing the individualist values among people from collectivist cultures like Indian and Korean. As a manifestation of such an influence, the heavy television viewers in India, for instance, are found to have individualist orientations - a change in their usual (collectivist) orientations. This finding brings to fore the fact that things are shifting around the world. Cultures these days are no more isolated, independent, and autonomous entities with unadulterated values and styles. The ground reality is that globalization is heavily influencing cultures in numerous ways. Due to cross-border flow of global forces, cultures, including communication styles, from around the world are increasingly encountering and grappling with one another resulting into homogenization, hybridization, localization and/or assimilation of cultures and cultural forces. What is significant about this cross/inter-cultural interaction or exchange is the mutual learning, reciprocal adoption/adaptation, and cross-fertilization of cultures happening in the process.

Notwithstanding the cross-cultural interactions and learning, globalization has its own limitations. For one, the process of globalization is lopsided because Western cultural patterns are dominating the world at this point. Many call this process a Westernization of the world cultures, which to a great extent, is true. This state of intercultural exchange is not ideal, I must confess, but I am interested more here at the mutual intercultural learning, adoption/adaptation and hybridization of communication styles than at the unequal exchange of cultural forces. One good outcome of the increasing intercultural contact and interaction is that people from across cultures now know and can shuttle between different cultural styles of 
communication. It is increasingly possible now that the same individual can, for instance, switch between American and Chinese style of communication depending on the demands of the communication contexts. Given such proficiency of the many interactants, it could be foolhardy for us to expect a stereotypical communication pattern from any group of people. Global, transnational or transcultural as the interactants have become in their ability to adopt and use different communication styles in different contexts, intercultural communication styles have now become more and more the rhetorical moves or choices interactants make depending on the situations than anything else.

While arguing along this line, I should, however, take caution to avoid any generalization that only intercultural contact triggered by globalization brought stylistic plurality or made the stylistic shuttling across contexts or cultures possible. Communication style as rhetorical move/choice is prevalent even within a (single) culture. Deniz Zeyrek (2001) provides one such instance in his article "Politeness in Turkish and its linguistic manifestations" where he notes that in Turkish cultures, "Individuals are expected to place group advantages before personal ones, even if this requires at times making sacrifices" (p. 44) but in "a closely-knit family structure, directness in speech prevails"(p. 44). Both direct and indirect communication styles prevalent in Turkish culture attests to the fact that plurality of style characterizes cultures. This Turkish instance also undermines the common assumption among intercultural scholars that Turkish culture is high-context in every way and Turkish communication style is always indirect. At the same time, this case also alerts us to the fact that cultures operate in complex ways and generalization and stereotyping of any kinds are risky and reductive.

Similarly interesting and critical is Yong-Jin Song and Claudia L. Hale's (2006) "The business negotiation styles of the Chinese, the Japanese, and South Koreans: Similarities and differences found in East Asian cultural groups" from the point 
of intercultural communication style as a rhetorical choice. This study is equally interesting from intracultural point of view too because it examines the negotiation strategies, styles and tactics of Chinese, Japanese, and South Korean negotiators - all the ones said to be high-context, high-power distance, and highuncertainty avoidance cultures. In Hall and Hofstede's schemes, they all fall into the same categories, but this study indicates otherwise. Their negotiation styles are found so much different from one another that the typical cultural schemes just fall flat. According to the authors, the characteristics of Chinese negotiation team are: Large team with vague authority; price sensitive; contract to start a relationship and use of double standards. Its styles/strategies are mostly dominating and distributive while the tactics are: exploiting agreed principles; using location; masking interests; stalling, limited authority; auction; good cop-bad cop; social/attrition; shaming; sudden change; showing anger; friendship means obligation; indifference; deadlines and distorting the record. Similarly, the characteristics of Japanese negotiation team are: 1. Indulgent dependency on the more powerful in a vertical relationship 2 . Group consensus 3. Victim mentality 4. Long-term approach 5. Contract to start a relationship 6. Indirect approach 7. In-group vs. outgroup distinction 8. Holistic approach 9. Use of introducer and mediator. Their Styles/Strategies are both integrative and soft competition and tactics are: 1. Long-term relationship 2. Harmony and face-saving 3. Politeness 4. Obligation/Pregiving 5. Banana sale approach 6. Contingent offer 7. Delaying 8. Persistence 9. Concealing the top man 10. Official stance vs. true mind 11. Using location and socializing 12. Emotion-drenched personal appeal (seller's approach). And finally, characteristics of South Korea are: 1. Mood or feelings important 2. Sincerity, good faith, and honesty important 3. Long-term approach 4. Repetitive and slow 5. In-group vs. outgroup distinction 6. Change of strategies 7. Big differences between big and small companies 8 . Success claimed after implementation of the contract 9. Group consensus 10. Hierarchical. Their styles/strategies are integrative with friends, distributive with enemies and tactics include: 1. Forthright 2. 
Pragmatic 3. Social 4. Brinkmanship 5. Uhm po (verbal threat) 6. Overwhelming 7. Legalistic 8. Self-righteous.

So many variations in characteristics, strategies and tactics among them! I don't think any further explanation along this line is needed. However, one striking note these authors make that I want to discuss a little further and that also reinforces my line of argument is:

Cultural stereotypes do not always hold true in negotiations and to act on their basis limits the flexibility one has (Weiss et al., 1996). What makes describing national negotiation styles even more challenging is that negotiators behave somewhat differently in intercultural versus intracultural situations. (p. 268-69)

What better description of intercultural communication style as rhetorical choice could there be than this one. Interactants in intercultural communication contexts are also kind of negotiators. They make different rhetorical choices and decisions when communicating with intercultural interactants as much as they do also while communicating with interactants from within their own cultures.

The authors also report that the styles, strategies, and tactics of three cultures/nations are identified mostly in the context of "business negotiations" "with U.S. Americans." In other words, these negotiators' styles, strategies, and tactics employed in non-business negotiation situations or with non-Americans could be totally different. There is every possibility for this to be the case because communication styles, tactics or strategies are not static and predictable, but always dynamic and situational acts. Individuals from any culture can switch their styles depending on who their interactants are or can employ or call into play different styles and strategies in different intercultural and intracultural communication contexts. So labeling their styles as one or the other in definite terms is problematic precisely because communication style-both 
intracultural and intercultural - is a rhetorical move, which can vary across situations/contexts.

The notion of inter/cultural communication style as a rhetorical choice brings us to the point that intracultural stylistic differences are as glaring as intercultural ones. There has already been voice raised about this but has so far been clouded by the prominent voice about generalizable cultural styles of communication. For example, many "feminist scholars such as Marsha Houston (1992), Patricia Hill Collins (1993), and bell hooks (1989) argue that inquiry must address interlocking and overlapping nodes of identity (i.e. race, class, and gender) rather than focus on any one node alone" (Moon, 2008, p. 17). Their contention is that intercultural communication must take into account the intracultural gender, race and power-relations issues and their impact on communication styles while talking about intercultural communication difference because intercultural communication style is shaped equally by these intracultural differences. This line of reasoning is also furthered by Moefl Asante (2008) in his "The Ideological Significance of Afrocentricity in Intercultural Communication" where he argues: "the power relationships dictate so much of what is right, correct, logical, and reasonable in communication. The limits are drawn by those who wield the economic, political, and cultural power" (p. 48). That is why he proposes: "effective intercultural communication must be based upon the equality of the interactants because the sharing of meaning is the fundamental prerequisite of communicative understanding" (Asante, p. 48). The socio-economic and demographic factors that feminist scholars foreground and the unequal powerrelations that Asante highlights are extremely relevant to intercultural communication as they are to communication in general because the former is as much affected and shaped by them as the latter one is.

This discussion of intracultural variables of communication style connects so smoothly with Co-cultural theory of intercultural communication, which can be instrumental in 
grounding intra- and inter-cultural power and other inequalities influencing communication styles. Co-cultures include, but not limited to, nonwhites, women, people with disabilities, homosexuals, and those in the lower classes. These groups of people are always at the lower end of the communication pyramid. They are also the ones forced to adjust, adapt or change their behaviors to fit in mainstream cultures. So, communication style for individuals from these disadvantaged communities is usually a transcultural phenomenon. Their rhetorical situations have more impact on their communication styles than their cultural orientations or values. It would be wrong to claim however that these groups do not know their cultural values and cannot use their cultural communication styles. No doubt, they know their values and can and do smoothly use their cultural communication styles while in comfort of their homes or close communities, but switch or adjust them accordingly when the rhetorical situations require them to do so. This case of co-cultures further justifies my point that inter/cultural communication style is rhetorical move on part of the interactants. It also forces us to think more about the role of power-relations in intercultural communication style, which Winfried Thielmann (2010) explicitly discusses in his article "Power and Dominance in Intercultural Communication." For him, issues of power and dominance make a real difference in communication style. In many cases like that of teacher-student, doctor-patient or agent-client communication, one in the lower end compromises the most in terms of their communication styles. These interactions are also equally compounded by asymmetries of knowledge level. "Hence for an understanding of power and dominance in intercultural communication, societal organization and actants' knowledge are crucial factors to be considered in the analysis" (Thielmann, p. 105). Thielman reinforces one point again and again that whether in intra or intercultural communication context, it is the interactants in the lower end of the spectrum who "adjust, modify and expand their cultural apparatus to make this communication work" (p. 109). So, it becomes evident that intercultural communication style gets shaped and 
reshaped by many variables other than just the cultural ones or, in other words, interactants' stylistic choices are determined as much by power-relations and audience-speaker-context dynamics and such as by cultural values and norms, which is to say that communication style - both cultural or intercultural-is largely a rhetorical choice.

My argument also resonates with Lise M. Sparrow's (2000) essay "Beyond Multicultural Man: Complexities of Identity" where she talks about complex individual identity and multiple subject positions which makes it hard to generalize any individual and his/her behaviors. According to her, females, for instance, "tend to move from their grounding in gender, ethnicity, religion and race into the multiple and dynamic circumstances which serve to further affect and shape their identities" (p. 254). Given these multiple identities and subject positions of each individual, it is not unusual to expect her/him to use different communication styles in response to different communication situations. This is exactly what Elizabeth Gareis (2000) in "Rhetoric and Intercultural Friendship Formation" implies when she says (citing Ron Scollon and Suzanne Scollon) that "Not only do individuals belong to multiple discourse systems through ethnic, generational, gender, and other group or personal differences, it is really hard to generalize any individual or culture" (p. 115). As hard it is to generalize any individual and her/his culture, it is even harder to generalize her/his communication style. This nongeneralizability of individuals, their cultures and their communication styles has associative connection with Ron Scollon and Suzanne Wong Scollon's notion of discourse community. Scollon and Scollon contend that even a single culture can have multiple discourse communities and each discourse community has its own set of communicative conventions called discourse conventions. That being the reason, they call any kind of communication, let alone intercultural communication, interdiscoursal communication. In fact, the notion of discourse community is very significant in analyzing intercultural communication styles. An instance of 
different discourse communities operating within a culture is evident in Ajay K. Ojha's (2003) "Humor: A Distinctive Way of Speaking That Can Create Cultural Identity." Specifically, this essay discusses a joke that is used by Asian Indians to refer to Asian Indian Americans (and vice versa) and how that splits the same community/culture into two distinct groups (in group/out group). "ABCD” (America Born Confused Desi) joke among Asian Indian Americans and "FOB" (Fresh off the Boat) joke among Asian Indians are familiar and intelligible within the groups but not across groups, which means that even within the same culture (both groups are Indians) discourse communities are not able to communicate. As mentioned above, discourse community is no doubt a useful notion, but it still generalizes communication style because it imagines a group of people sharing same set of communicative/discursive conventions, which stands opposed to my formulation here that communication acts/styles are not at all generalizable.

Therefore, because every individual uses his/her rhetorical resources differently across different communicative situations, it has already been time to think about replacing the "opposing categories, "inter-cultural" versus "intracultural," with "degree of interculturalness" on a continuum of heterogeneity/homogeneity. As Ringo Ma (2005) argues, "[T]he degree of heterogeneity between Hong Kong and Mainland Chinese should be no less than that between AngloAmericans and Anglo-Canadians" (p. 201); the individual difference of all kinds has impact in both cultural and intercultural communication styles. Even more than individual difference is the rhetorical choices of the individuals across communicative situations that make any predictions about their communicative behaviors impossible and problematic too. So, it is time long overdue to leave behind any generalizing feats and establish the fact in the field that intercultural communicative style is genuinely a rhetorical choice. 


\section{References}

Asante, M. K. (2008). The ideological significance of Afrocentricity in Intercultural Communication. In Molefi Kete Asante, Molefi Kete and Yoshitaka Miike and Jing Yin (Eds.), The Global Intercultural Reader (pp. 47-56). New York and London: Routledge Taylor and Francis Group.

Avtgis, T. A., \& Rancer, Rancer, A. S. (2002). Aggressive communication across cultures: A comparison of aggressive communication among United States, New Zealand, and Australia. Journal of Intercultural Communication Research, 31 (3), 191-200.

Avtgis, T. A., \& Rancer, Rancer, A. S. (2003). Comparing touch apprehension and affective orientation between AsianAmerican and European-American siblings. Journal of Intercultural Communication Research, 32 (2), 67-74.

Barnlund, D. (1998). Communication in a global village." In Milton J. Bennett (Ed.), Basic Concepts of Intercultural Communication: Selected Readings (pp. 35-52). Maine: Intercultural Press.

Feghali, E. (1997). Arab cultural communication patterns. International Journal of Intercultural Relations, 21(3), 345-378.

Feng, B., \& Burleson B. R. (2006). Exploring the support seeking process across cultures: Toward an integrated analysis of similarities and differences. International and Intercultural Communication Annul, 29, 243-266.

Gareis, E. (2000). Rhetoric and Iintercultural friendship formation. In Alberto Gonzalez, and Dolores V. Tanno (Eds.) Rhetoric in Intercultural Contexts (91-118). Thousand Oaks: Sage Publications, Inc.

Kapoor, S., Konsky, C, \& Blue J. (1997). American and Indian students' preference for horizontal and vertical individualism-collectivism. World Communication, 26 (1), 14-29.

Knutson, T. J., Komolsevin R., Chatiketu P., \& Smith V. R. (2002). A comparison of Thai and U.S. American willingness to communicate. Journal of Intercultural Communication Research, 31(1), 3-12. 
Ma, R. (2005). Communication between Hong Kong and Mainland Chinese: Rethinking cross-cultural adaptation. International and Intercultural Communication Annul, 28, 197-213.

Moon, D. G. (2008). Concepts of "Culture": Implications for intercultural communication research. In Molefi Kete Asante, Molefi Kete and Yoshitaka Miike and Jing Yin (Eds.), The Global Intercultural Reader (pp. 11-26). New York and London: Routledge Taylor and Francis Group.

Ojha, A. K. (2003). Humor: A distinctive way of speaking that can create cultural identity. Journal of Intercultural Communication Research, 32.3/4, 161-174.

Ramsey, S. J. (1998). Interactions between North Americans and Japanese: Considerations of communication style. In Milton J. Bennett (Ed.), Basic Concepts of Intercultural Communication: Selected Readings (pp. 111-130). Maine: Intercultural Press.

Scollon, R.. \& Scollon S.W. (2001). Intercultural Communication: A Discourse Approach ( $2^{\text {nd }}$ ed.). Malden, MA: Blackwell Publishers Inc.

Song, Y., \& Hale, C. L. (2006). The business negotiation styles of the Chinese, the Japanese, and South Koreans: Similarities and differences found in East Asian cultural groups.

International and Intercultural Communication Annul, 29, 267-292.

Sparrow, L. M. (2000). Beyond multicultural man: Complexities of identity. International Journal of Intercultural Relations, 24 (2), 173-201.

Thielmann, W. (2010). Power and dominance in intercultural communication. In David Matsumoto (Ed.), $A P A$ Handbook of Intercultural Communication (pp. 105-122). Washington D.C.: American Psychological Association.

Zeyrek, D. (2001). Politeness in Turkish and its linguistic manifestations: A socio-cultural perspective. The Linguistic Politeness across Boundaries: the case of Greek and Turkish, xiv, 43-73.

The author is pursuing $\mathrm{PhD}$ at Syracuse University, USA. 